\title{
Fibrinogen levels helps in early detection of abnormal pregnancies
}

\section{Kanchana A.*, Girijavani DSS}

Department of Biochemistry, GIMSR, Vishakhapatnam, Andhra Pradesh, India

Received: 03 November 2016

Accepted: 30 November 2016

\author{
*Correspondence: \\ Dr. Kanchana A., \\ E-mail: kanchanaangati@yahoo.co.in
}

Copyright: ( ) the author(s), publisher and licensee Medip Academy. This is an open-access article distributed under the terms of the Creative Commons Attribution Non-Commercial License, which permits unrestricted non-commercial use, distribution, and reproduction in any medium, provided the original work is properly cited.

\begin{abstract}
Background: Haemostatic failure as an end result of various complications of pregnancy is an important cause of maternal mortality in India. The main aim of this study is to detect the levels of fibrinogen in abnormal pregnancy i.e. Pregnancy induce hypertension (PIH), Intra uterine fetal death (IUFD), Missed abortion, Abruptio placenta.

Methods: Study was conducted on 150 in patients joined in Obstetrics ward private hospital, Andhra Pradesh, 50 are control subjects and 100 are study patients, Out of hundred (100) cases, 40 are PIH, 25 are IUFD, 25 are Missed abortion, and 10 are Abruptio placentae. Estimated for fibrinogen, D-Dimer, total proteins, Albumin.

Results: The fibrinogen levels in present study decreased significantly. PIH (Control mean 442.0, S.D \pm 43.38 , Test mean 296.0, S.D \pm 48.03 , p<0.001). IUFD (Control mean 442.0, S.D \pm 43.38 , Test mean 262.4, S.D $\pm 20.06, p<0.001$ ). Missed abortion (Control mean 442.0, S.D \pm 43.38 , Test mean 250.80, S.D $\pm 26.13, \mathrm{p}<0.001$ ). Abruptio placentae (Control mean 442.0, S.D \pm 43.38 , Test mean 210.5, S.D $\pm 87.38, \mathrm{P}<0.001$ ). D-dimer levels are estimated semi quantitatively and the levels were found to be increased. Total proteins and albumin are decreased in all the cases, but significantly in PIH (T.P-Control mean6.25, S.D \pm 0.65 , Test mean 5.25, S.D \pm 1.57 , p <0.001, Albumin- Control mean 2.79, S.D \pm 0.34 , Test mean 2.23, S.D \pm 0.59 , p<0.001).

Conclusions: The estimation of plasma fibrinogen is helpful not only in the early diagnosis of haemostatic failure but also to guide replacement therapy during the fibrinopenic state.
\end{abstract}

Keywords: Abruptio placenta, IUFD, Missed abortion, PIH

\section{INTRODUCTION}

Haemostatic failure as an end result of various complications of pregnancy is an important cause of maternal mortality in India. Incidence of maternal mortality in India due to complications during pregnancy and child birth is $17.5 \%$ (Out of 3, 58,000 globally $63,000$ deaths occur in India. $)^{1}$.

Understanding of abnormalities of coagulation parameters and their significance in various obstetric emergencies mandates thorough knowledge of not only normal physiology of blood clotting mechanism but also physiological changes in pregnancy and pathophysiology of such obstetric conditions. In following sections, we shall discuss etiopathogenesis and clinical significance of coagulation abnormalities in missed abortion, abruptio placentae, pregnancy induced hypertension (PIH) and intra uterine fetal demise (IUFD).

\section{Physiology of blood coagulation ${ }^{15,16,25}$}

Coagulation factors in blood are present in inactive state and an appropriate stimulus like endothelial damage or tissue damage prompts activation of coagulation cascade which limits loss of blood by formation of blood clot. Simultaneously another system of anticoagulants work in tandem with clotting system to limit unwanted extension of this clot to normal sites. Delicate balance of both these systems is necessary to maintain homeostasis. 
The loose aggregation of platelets in temporary plug is bound together and converted into the definitive clot by fibrin. The clotting mechanism responsible for formation of fibrin involves a cascade of reactions in which inactive enzymes are activated, and the activated enzymes in turn activate other inactive enzymes

The fundamental reaction in the clotting of blood is conversion of soluble plasma protein fibrinogen into insoluble fibrin.

\section{Physiological changes during pregnancy ${ }^{17,27}$}

Pregnancy is a physiological state, where changes occur virtually in every organ system and blood is not an exception. Coagulation system changes create a hypercoagulable state. Main reason for this state is increase in plasma levels of fibrinogen. Normal levels of fibrinogen are $200-400 \mathrm{mg} / \mathrm{dl}$, where as in pregnancy fibrinogen levels reach up to $600 \mathrm{mg} / \mathrm{dl}$. Also there is increase in activities of factors II, VII, VIII, IX, $\mathrm{X}^{34}$. Anticoagulants like protein $\mathrm{C}$, protein $\mathrm{S}$ and antithrombin III are present in decreased levels. As a result of this, there is increase in fibrinogen and other clotting factors and depressed fibrinolytic activity, a hypercoagulable state is created. Accelerated intra vascular coagulation serves to maintain utero-placental interface. These changes in coagulation system minimize blood loss by effective haemostatic mechanisms after separation of placenta.

\section{Disseminated intravascular coagulation $(D I C)^{2,17}$}

DIC is an acute or chronic thrombo hemorrhagic disorder occurring as a secondary complication of variety of diseases. It is characterized by activation of coagulation sequence that leads to formation of microthrombi throughout the micro circulation of the body. As a consequence of the thrombotic diathesis, there is consumption of platelets, fibrin and other coagulation factors. Thus this disorder is also called consumption coagulopathy. Secondarily, there is activation of fibrinolytic mechanisms to remove the clots from microcirculation. Etiology of DIC is wide and includes various obstetric and non-obstetric conditions show in Table 1.

The consequences of DIC are, First there is wide spread deposition of fibrin within the micro circulation leading to tissue hypoxia and ischemia. Fragmentation of red blood cells squeezing from these vessels can lead to hemolysis (micro angiopathic hemolytic anemia). Second, as result of uncontrolled clot formation, platelets and coagulation parameters are consumed at rate greater than the rate of their production. This leads to hemorrhagic diathesis. In addition fibrinolysis leads to formation of fibrin degradation products, which inhibit platelet aggregation and fibrin polymerization. All these lead to haemostatic failure in DIC.
Here we shall discuss four obstetric conditions which are associated with abnormalities on coagulation parameters.

- Intra uterine fetal death (IUFD)

- Abruptio Placentae

- Pregnancy Induced Hypertension (PIH)

- Missed Abortion.

\section{Intra uterine fetal death $(\text { IUFD })^{8,17,28}$}

Involuntary loss of pregnancy at any period of gestation is fetal demise. Fetal death as defined by WHO in 1950 and revised by the working group formed by the American academy of pediatrics and American college of Obstetricians and Gynecologists in 1998, is "death prior to complete expulsion or extraction from its mother of a products of human conception, irrespective of the duration of pregnancy and which is not an induced termination of pregnancy". The death is indicated by the fact that after such expulsion or extraction, the fetus does not show any evidence of life such as heart beats, definite movements of voluntary muscles, umbilical cord pulsations.

Clinically IUFD is suspected when mother reports loss of fetal movements. Clinical signs like gradual regression of fundal height, loss or diminished uterine tone and inability to feel fetal movements and inability to hear fetal heart sound support the diagnosis of IUFD. Egg shell crackling of fetal head is a late sign. The diagnosis of IUFD can be confirmed by ultrasound Doppler by noting the absence of fetal heart activity.

It has been discussed above that if fetus is retained for more than 4 weeks (as in 20\% of cases) there is possibility of defibrination from silent disseminated intravascular coagulation (DIC). This is due to gradual absorption of thromboplastin, liberated from dead placenta and decidua, into the maternal circulation. Although IUFD might lead to DIC, frequently the underlying cause for IUFD such as HELLP syndrome, preeclampsia or placental abruption themselves might be associated with DIC.

Incidence of coagulopathy in IUFD is determined by 2 factors cause of IUFD and duration of retained dead fetus.

\section{Abruptio placentae $e^{3,8,17}$}

Separation of the placenta from its implantation site before the birth of fetus is called Abruptio placentae. This entity has been variously termed as accidental hemorrhage and ablation placentae in the literature.

Its incidence is $1.5 \%$ in all pregnancies and it falls to $0.3 \%$ in full term pregnancies. Incidence of abruptio placentae in India has been found to be 0.2 to $2 \%$. Retroplacental clot is detected post-partum in $4.5 \%$ of cases. 
The initial event in abruptio placentae is bleeding into deciduas basalis. The retro-placental hematoma/ hemorrhage formed separate the placenta from the maternal vascular system causing impairment in fetal oxygenation and nutrition

It has been suggested that, first, a retroplacental clot forms and may build up sufficient pressure to cause abruptio placentae. In full blown abruptio placentae, uterine size may be larger than term uterus and contains a large retroplacental clot which might have tracked beyond the confines of placental margin. Blood may track down and bleeding per vaginum can be a presenting symptom. Then it is called revealed abruptio placentae. Bleeding may be intrauterine and no blood appears at vulva, called concealed abruptio placentae. More commonly a mixed variety is seen with both the features. In concealed abruptio placentae blood clot may even burst into amniotic sac (port wine colored amniotic fluid). The blood may dissect into myometrium towards serosa resulting in full blown picture of Couvelaire uterus (uteroplacental apoplexy). It may show characteristic echhymosis on the serosa. Bleeding may occur between the layers of broad ligament. Peritoneal cavity contains blood stained fluid and in rare cases, uterus may actually rupture into peritoneal cavity leading to massive intra peritoneal bleed.

The resulting laceration in the decidual layers also allows free communication from the intra decidual space of the hematoma into the maternal circulation of the placenta. There now follows a process in which tissue substances including thromboplastin from decidual layers enter directly into maternal circulation leading to coagulopathy.

As evident from above discussion, abruptio placentae can be associated with abnormalities in coagulation cascade ranging from mild changes to fulminant DIC. The grade of abruption and magnitude of abnormalities in lab parameters correlate to a large extent and hence DIC can be seen in cases of severe abruptio placentae.

\section{Pregnancy induced hypertension $(\text { PIH })^{8,17,19}$}

There is no antecedent history or any documentation that the woman had hypertension prior to pregnancy. The hypertension develops as a direct result of gravid state. It is divided into three clinical types:

- Pre- eclampsia

- Eclampsia

- Gestational Hypertension

Incidence in hospital practice varies widely from 5$15 \%$. The incidence in primigravidae is about $10 \%$ and in multigravidae $5 \%$.

In pre-eclampsia ${ }^{18}$ Imbalance of different components of prostaglandins- relative or absolute deficiency of vasodilator prostaglandin $\left(\mathrm{PGI}_{2}\right)$ synthesized in vascular endothelium and increased synthesis of thromboxane $\left(\mathrm{TXA}_{2}\right)$, a potent vasoconstrictor in platelets.

Coagulation: Evidence of disseminated intravascular coagulopathy DIC affecting wide spread organs, due to release of trophoblastin into the circulation. It may arise from the blood platelets as in Shwartzman reaction or from release of trophoblastic fragments into the uterine circulation. There is reduction of platelets, Fibrinogen, antithrombin III and plasminogen levels in the blood. Microthrombi affect the arterioles of all the vital organs apart from the placenta. Degree of thrombocytopenia reflexes the severity of pathology. Fibronectin and thrombin levels are elevated.

\section{Missed abortion}

\section{Definition of abortion ${ }^{4,17}$}

Abortion is the termination of pregnancy before the period of viability which is considered to occur at $28^{\text {th }}$ week. The limit of viability is brought down to either $20^{\text {th }}$ week or fetus weighing $500 \mathrm{gm}$.

Incidence: The incidence of miscarriage is about $10 \%$. $75 \%$ abortion occurs before $16^{\text {th }}$ week and of these about $75 \%$ occurs before the $8^{\text {th }}$ week of pregnancy.

Blood coagulation disorders: If fetus is retained for more than 4 weeks there is possibility of defibrination from silent disseminated intravascular coagulopathy (D.I.C). It is due to gradual absorption of thromboplastin, liberated from dead placenta and deciduas, into the maternal circulation. 3. Psychological upset 4. During laborUterine inertia, retained placenta and postpartum haemorrhage.

The main aim of this study is to detect levels of fibrinogen levels in the abnormal pregnancy. Which is main blood component in clot formation, other parameters like D-dimer, total protein and albumin are also estimated

\section{METHODS}

In the present study 150 cases admitted in obstetric ward for delivery were studied (control 50 and cases 100) with following parameters, Plasma fibrinogen, d-dimer, Total protein, Albumin. The mean age group of patients is 25 years, during the period of 2014-2015. Out of hundred pregnancies forty 40 are $\mathrm{PIH}, 25$ are Missed abortion, 25 are IUD, 10 are Abruptio Placenta. Fifty (50) healthy control of normal pregnancy who are admitted for delivery of similar time. Statistics analysis is done for $p$ value.

Plasma fibrinogen is estimated by Tulip fibroquant method. $3,4,9-11$ 


\section{Procedure for fibrinogen calibrator curve}

1. The thrombin reagent vial reconstituted exactly with one $\mathrm{ml}$ of DW wait for $15 \mathrm{~min}$. Now it is ready to use for the fibrinogen test.

2. The Fibrinogen Calibrator vial reconstituted with exactly one $\mathrm{ml}$ of DW, Wait for $15 \mathrm{~min}$. This is the Fibrinogen Calibrator stock solution.

3. $1: 5,1: 10$, and 1:20 etc., dilutions of fibrinogen calibrator solution are prepared (eg: $0.05 \mathrm{ml} \mathrm{Std+}$ $0.95 \mathrm{ml}$ Buffer for $1: 20,0.1 \mathrm{ml}+0.9 \mathrm{ml}$ of std and Buffer resp. for 1:10 dilution etc) and added as in the table.

4. Pipette into labelled test tubes A, B, C, D, and E for standards and do.

Take $0.2 \mathrm{ml}$ of Fibrinogen Calibrator dilution into test tube from each std tube and add $0.1 \mathrm{ml}$ of reconstituted thrombin reagent and simultaneously start stopwatch. Stop the stopwatch at the first appearance of the fibrin web, as the gel clot beings to form and record the time in seconds.

The time against the fibrinogen concentration is plotted on the graph paper Fig: 1 provided by the kit itself and points are connected which gave a straight line.

\section{Procedure for testing the sample}

Plasma $100 \mu 1$

\section{Owren's Buffer $900 \mu 1$}

Take $200 \mu \mathrm{l}$ from the above solution and incubate at $37^{\circ} \mathrm{C}$ for one minute and add $100 \mu \mathrm{l}$ of pre warmed $\left(37^{\circ} \mathrm{C}\right)$ thrombin reagent and immediately start the stopwatch. Stop the stopwatch as the gel clot being to form and record the time in seconds and read the concentration of fibrinogen from time in seconds form the fibrinogen calibrator curve graph paper.

If fibrinogen content is high the clotting time will be lessand if the less fibrinogen clotting time will be more.

Normal Range: $150 \mathrm{mg}-400 \mathrm{mg} / \mathrm{dl}$

D-Dimer is estimated by Tulip XL FDP D-Dimer ${ }^{5,12,13}$

\section{Semi quantitative method}

- Using PBS buffer solution prepare serial dilution of the plasma sample 1:2, 1:4, 1:8, 1:16, and so on.

- Pipette each dilution of plasma specimen onto the separate circles.

- $\quad$ Add one drop of XL FDP latex reagent to each drop of diluted plasma specimen onto the slide. Do not let the dropper tip touch the diluted plasma specimen on the slide.
- Immediately start the stopwatch, Rock the slide gently, back and forth, observing for agglutination macroscopically at three minutes.

- Agglutination in the highest plasma dilution corresponds to the approximate amount of $\mathrm{D}$ dimer level in $\mathrm{ng} / \mathrm{ml}$.

- To calculate $\mathrm{D}$ dimer level in $\mathrm{ng} / \mathrm{ml}$ in the sample, use the following formula.

- D dimer level $\mathrm{ng} / \mathrm{ml}=200 \times \mathrm{d}$

- $\mathrm{d}=$ highest dilution of plasma showing agglutination during the semi quantitative test of the sample.

Total protein and albumin is estimated quantitatively in fully automated analyser EM360 Transasia by using ERBA kits.

\section{RESULTS}

The fibrinogen levels in present study decreased significantly. PIH (Control mean 442.0, S.D \pm 43.38 , Test mean 296.0, S.D \pm 48.03 , p <0.001). IUFD (Control mean 442.0, S.D \pm 43.38 , Test mean 262.4, S.D \pm 20.06 , $\mathrm{p}<0.001$ ). Missed abortion (Control mean 442.0, S.D \pm 43.38 , Test mean 250.80, S.D \pm 26.13 , p<0.001). Abruptio placentae (Control mean 442.0, S.D \pm 43.38 , Test mean 210.5, S.D $\pm 87.38, \mathrm{P}<0.001)$. D-dimer levels are estimated semi quantitatively and the levels were found to be increased. Total proteins and albumin are decreased in all the cases, but significantly in PIH (T.P-Control mean6.25, S.D \pm 0.65 , Test mean 5.25, S.D \pm 1.57 , $\mathrm{p}<0.001$, Albumin- Control mean 2.79, S.D \pm 0.34 , Test mean 2.23, S.D \pm 0.59 , p<0.001).

Table 1: Major disorders associated with DIC.

\begin{tabular}{|ll|}
\hline Obstetric conditions & Non-obstetric conditions \\
Abruptio placenta & \\
Pre-eclampsia and & \\
eclampsia & \\
IUFD & Infections \\
Missed abortion & Neoplasms \\
Septic abortion & Massive tissue injury \\
Excessive blood loss & Miscellaneous conditions \\
Puerperal sepsis & \\
Amniotic fluid & \\
embolism & \\
\hline
\end{tabular}

Table 2: Standardization of fibrinogen levels.

\begin{tabular}{|llllll|}
\hline & $\mathrm{S}_{\mathrm{A}}$ & $\mathrm{S}_{\mathrm{B}}$ & $\mathrm{S}_{\mathrm{C}}$ & $\mathrm{S}_{\mathrm{D}}$ & $\mathrm{S}_{\mathrm{E}}$ \\
\hline Standard & $50 \mu \mathrm{L}$ & $100 \mu \mathrm{L}$ & $150 \mu \mathrm{L}$ & $200 \mu \mathrm{L}$ & $250 \mu \mathrm{L}$ \\
\hline Calibrator & 130 & 260 & 390 & 520 & 650 \\
Conc. & $\mathrm{mg} \%$ & $\mathrm{mg} \%$ & $\mathrm{mg} \%$ & $\mathrm{mg} \%$ & $\mathrm{mg} \%$ \\
\hline Owren's & 950 & 900 & 850 & 800 & 750 \\
Buffer & $\mu \mathrm{l}$ & $\mu \mathrm{l}$ & $\mu \mathrm{l}$ & $\mu \mathrm{l}$ & $\mu \mathrm{l}$ \\
\hline
\end{tabular}




\section{DISCUSSION}

In pregnancy complicating disease like Abruptio placentae, pregnancy induced hypertension, Intra uterine death and missed abortion common terminal complication is occurrence of $\mathrm{DIC}^{2,4}$ which is responsible for maternal mortality.

After the onset of clinical manifestation, the diagnosis of DIC is simplified but the treatment becomes difficult. Thus it is important to diagnose DIC at its subclinical stage so that early therapeutic measures can be instituted. The estimation of plasma fibrinogen is helpful not only in the early diagnosis of haemostatic failure but also to guide replacement therapy during the fibrinopenic state. ${ }^{7}$
In the present study we studied 100 cases of abnormal pregnancies, out of them pregnancy induce hypertension (40), Intra uterine death (25), Missed abortion (25), Abruptio placetae (10), the plasma fibrinogen levels is decreased compared to normal pregnant woman.

In Abruptio placentae (10 cases) the fibrinogen levels in our study decreased more significantly compared to other condition (plasma levels $210 \mathrm{mg} / \mathrm{dl}, \mathrm{p}<0.001$ ). Our study is supported by Memon FA, Noorani $\mathrm{KJ}^{9}$, Parasnis $\mathrm{H}$, Raje B, Hinduja IN ${ }^{23}$, Wisot AL, Barczak $\mathrm{EM}^{30}$ One out of ten $(10 \%)$ developed DIC.

Table 3: Biochemical parameters in PIH.

\begin{tabular}{|lllllll|}
\hline Parameters & Mean & \multicolumn{1}{l}{ S.d } & \multicolumn{2}{c|}{ T-value } & P-value \\
& C & T & C & T & & $<0.001$ \\
\hline T.P & 6.25 & 5.25 & 0.65 & 1.57 & 4.053 & $<0.001$ \\
\hline Albumin & 2.79 & 2.23 & 0.34 & 0.59 & 5.530 & $<0.001$ \\
\hline Fibrinogen & 442.0 & 296.0 & 43.38 & 48.03 & 15.127 & \\
\hline
\end{tabular}

Table 4: Biochemical parameters in IUFD.

\begin{tabular}{|c|c|c|c|c|c|c|}
\hline \multirow[t]{2}{*}{ Parameters } & \multicolumn{2}{|l|}{ Mean } & \multicolumn{2}{|l|}{ S.d } & \multirow[t]{2}{*}{ T-value } & \multirow[t]{2}{*}{ P-value } \\
\hline & $\mathrm{C}$ & $\mathrm{T}$ & $\mathrm{C}$ & $\mathrm{T}$ & & \\
\hline T.P & 6.25 & 6.03 & 0.65 & 1.03 & 1.119 & 0.266 \\
\hline Albumin & 2.790 & 2.792 & 0.347 & 0.639 & 0.017 & 0.986 \\
\hline Fibrinogen & 442.0 & 262.4 & 43.38 & 20.06 & 19.629 & $<0.001$ \\
\hline
\end{tabular}

Table 5: Biochemistry parameters in missed abortion.

\begin{tabular}{|lllllll|}
\hline Parameters & Mean & & \multicolumn{1}{l}{ S.d } & \multicolumn{2}{c|}{ T-value } & P-value \\
& C & T & C & T & & 0.079 \\
\hline T.P & 6.25 & 5.99 & 0.65 & 0.45 & 1.777 & 0.746 \\
\hline Albumin & 2.79 & 2.75 & 0.34 & 0.55 & 0.324 & $<0.001$ \\
\hline Fibrinogen & 442.0 & 250.80 & 43.38 & 26.13 & 20.239 & \\
\hline
\end{tabular}

Table 6: Biochemistry parameters in missed abortion.

\begin{tabular}{|lllllll|}
\hline Parameters & Mean & & \multicolumn{1}{l}{ S.d } & \multicolumn{2}{c}{ T-value } & P-value \\
& C & T & C & T & & 0.013 \\
\hline T.P & 6.25 & 5.62 & 0.65 & 0.96 & 2.554 & 0.074 \\
\hline Albumin & 2.790 & 2.57 & 0.34 & 0.36 & 1.817 & $<0.001$ \\
\hline Fibrinogen & 442.0 & 210.5 & 43.38 & 87.38 & 12.687 & \\
\hline
\end{tabular}

In Abruptio placentae hypofibrinogenemia is due to free entering of decidual tissue thromboplastin from decidual layers to maternal circulation leading to coagulopathy. This is due to free communication from intradecidual 
space of the hematoma into maternal circulation of the placenta. 2,6

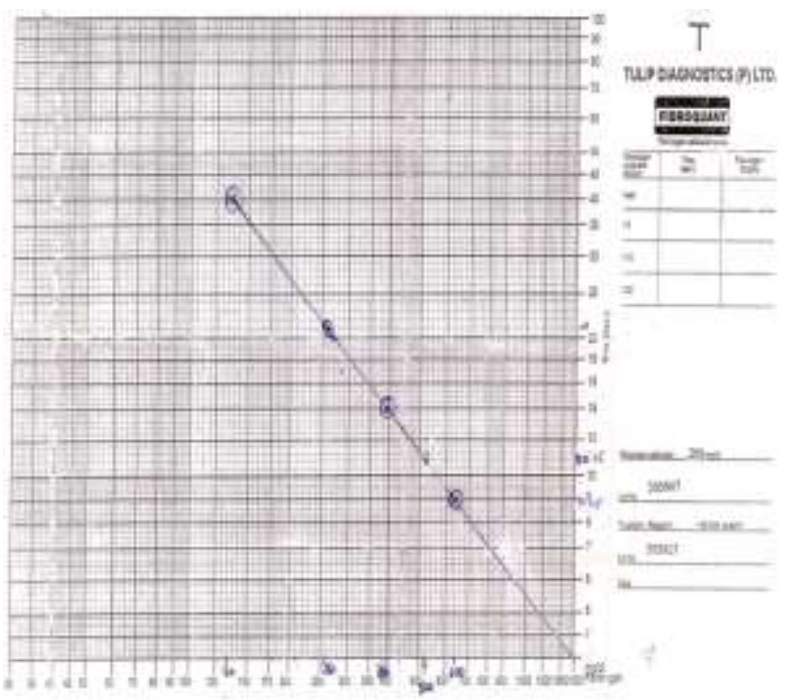

Figure 1: Fibrinogen concentration to time in second.

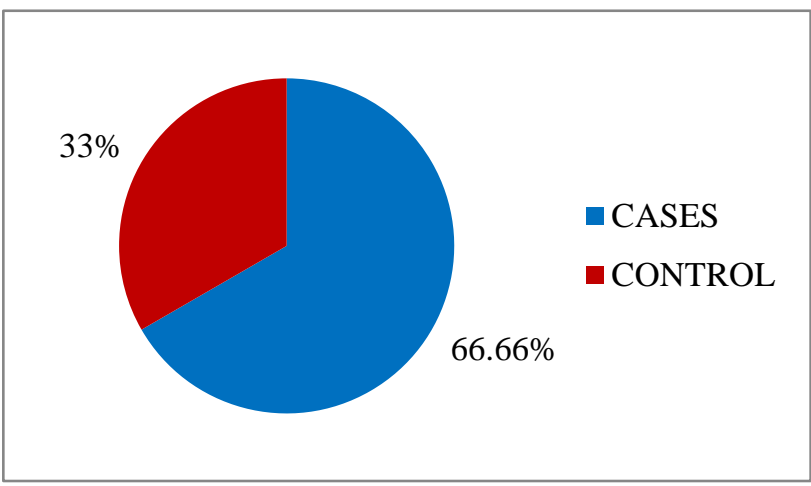

Figure 2: Pattern of distribution of cases and controls in the study.

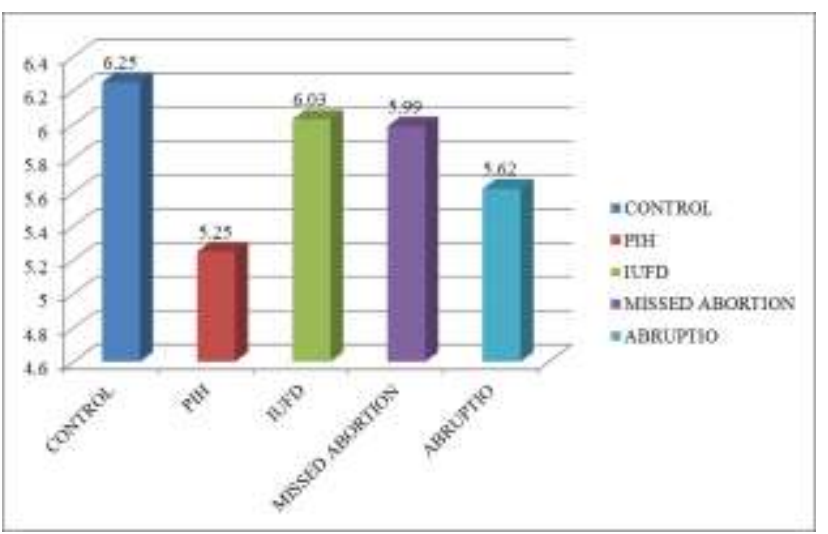

Figure 3: Comparison of total protein levels control and cases.

Hypofibrinogenemia associated with increased levels of fibrin degraded products (d-dimer), which inhibit myometrical contractility leading to postpartum hemorrhage. In present study d-dimer levels are estimated semi quantitatively which is raised significantly (plasma level 3200ng/ml) to normal pregnancy (plasma level (130- $1700 \mathrm{ng} / \mathrm{ml}$ ) our study supported by by Memon FA, Noorani $\mathrm{KJ}^{9}$, Nolan TE, Smith RP, Devoe LD. ${ }^{22}$

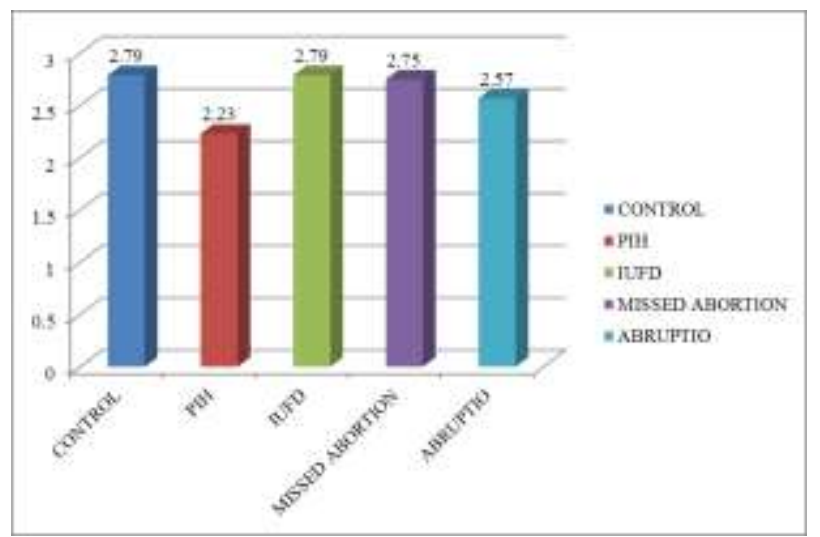

Figure 4: Comparison of albumin levels in control and cases.

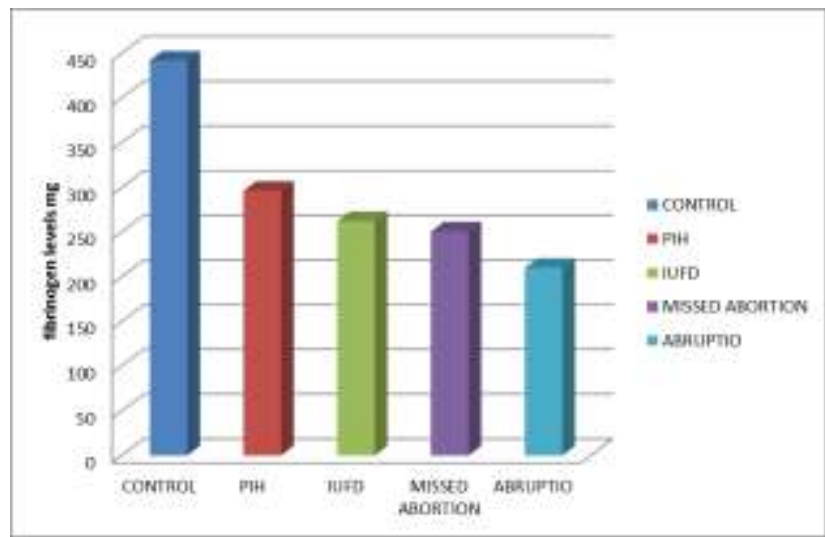

Figure 5: Comparisons of fibrinogen levels in control and cases.

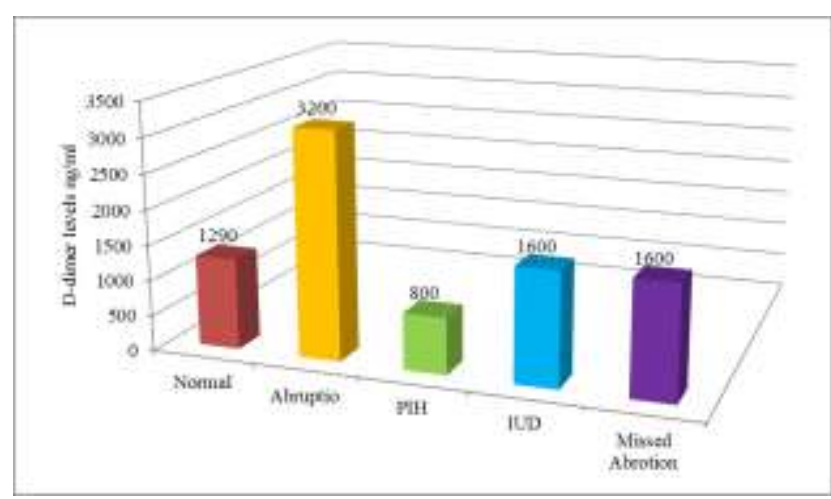

Figure 6: Comparison of D-DIMER levels in control and cases.

The levels of total protein and albumin are decreased in abruptio placentae then the normal pregnancy. ${ }^{5}$ 
In Intra uterine fetal death (25 cases) in our study show hypofibrinogenimia.10 of $25(40 \%)$ are <4 week and 15 are $>4$ weeks retained fetus intra uterine, (plasma level $262 \mathrm{mg} / \mathrm{dl}, \mathrm{p}<0.001$ ) our study is supported by $\mathrm{J}$ Womens Health (Larchmt). Maslow AD et ${ }^{\text {al7,21 }}$, Parasnis H, Raje $\mathrm{B}$, Hinduja $\mathrm{IN}^{23}$, Gochberg $\mathrm{SH}^{26}$

In Intra uterine fetal death hypofibrinogenemia is due to gradual absorption of thromboplastin, liberated from dead placenta and decidua, into the maternal circulation. ${ }^{2,6,14}$

The fibrin degraded products levels increased d-dimer levels (plasma levels-1600ng/ml) then the normal $\left(2^{\text {nd }}\right.$ trimester levels 320-1290ng/ml)our study supported by Bonnar J, Davidson JF, Pidgeon CF, McNicol GP, and. Douglas AS. ${ }^{10}$

In missed abortion (25 cases) in our study show hypofibrinogenemia (plasma level $250 \mathrm{mg} / \mathrm{dl}$ ) our study is supported by Parasnis H, Raje B, Hinduja $\mathrm{IN}^{23}$, Chandran $\mathrm{R}$, Adeeb N. ${ }^{24}$

The underling pathology for hypofibrinogenemia in missed abortion is similar to that of IUFD. ${ }^{13}$

d-dimer levels (plasma levels-1600ng/ml) then the normal ( $2^{\text {nd }}$ trimester levels 320-1290ng/ml)), total protein, albumin levels are decreased.

In pregnancy induce hypertension (40 cases) in our study show hypofibrinogenemia (plasma levels 296mg/dl). 15 of $40(37.5 \%)$ show normal levels. Our study supported by Yang M, Shen W, Chen $\mathrm{L}^{20}$, Schjetlein R, Haugen G, Wisløffv, Parasnis H, Raje B, Hinduja IN ${ }^{23}$, Trott EL ${ }^{29}$, Mary Part Fitzgerald, Floro C, Siegel J, MD, Enrique Hernandez. $^{32}$

D-dimer levels are increased in PIH plasma levels $800 \mathrm{ng} / \mathrm{dl}$ or normal ( $2^{\text {nd }}$ trimester levels $320-1290 \mathrm{ng} / \mathrm{ml}$ ) study supported by Eichinger $\mathrm{S}^{33}$ Nolan TE, Smith RP, Devoe LD. ${ }^{22}$

Total protein (serum level $5.25 \mathrm{mg} / \mathrm{dl} \mathrm{p}<0.001$ ) decreased and albumin decreased (serum level $2.23 \mathrm{mg} / \mathrm{dl}, \mathrm{p}<0.001$ ) Seong WJ, Chong GO, Hong DG, Lee TH, Lee YS, Cho YL, Chun SS and Park IS, Mack HC. ${ }^{6,31}$

\section{CONCLUSION}

The estimation of plasma fibrinogen is helpful not only in the early diagnosis of haemostatic failure but also to guide replacement therapy during the fibrinopenic state.

Funding: No funding sources

Conflict of interest: None declared

Ethical approval: The study was approved by the Institutional Ethics Committee

\section{REFERENCES}

1. Desai S. India makes progress on reducing maternal mortality rate, 2010.

2. Baskett T, Darrien Rattray PG. Disseminated intravascular coagulation in pregnancy, 2010.

3. Dulay AT. Abruptio placentae, Merck manual, 2010.

4. Puscheck EE. Professor, Department of Obstetrics and Gynecology, Wayne State University School of Medicine; Missed abortion, 2010.

5. Khan S. d-dimer normal range, 2010.

6. Seong WJ, Chong GO. Clinical significance of serum albumin level in pregnancy-related hypertension. Journal of Obstetrics and Gynecology Research. 2010. DOI: 2010.01296.x10.1111/j.1447-0756.

7. Nachtigall MJ. Toward optimal health: an update on preconception care. Interview by Jodi R. Godfrey. J Womens Health (Larchmt). 2009;18(6):779-83.

8. Ian Donald's Practical Obstetrics problems, 6th Edition, 2009.

9. Khooharo Y, Memon FA, Noorani KJ. Disseminated intravascular coagulation in Abruptio Placentae. Pak J Med Sci. 2009;25(4):660-3.

10. Mosby's Medical Dictionary, Elsevier, Missed abortion, 8th Edition, 2009.

11. Abbassi-Ghanavati M, Greer LG, Cunningham FG. Pregnancy and laboratory studies: a reference table for clinicians for d-dimer. Obstet Gynecol. 2009;114(6):1326-31.

12. Vasudevan's Text book of Biochemistry, 5th Edition, 2009.

13. Hall DR. Abruptio placentae and disseminated intravascular coagulopathy. Semen Prenatal. 2009;33(3).

14. Chatterjee's Text book of Biochemistry, 7th Edition, 2007.

15. Guyton and Hall Text book of Medical Physiology, 10th Edition, 2005.

16. Harold R. Robert Dougald Williams Hematology 6th Edition, 2004.

17. Dutta DC. Text book of Obstetrics, 6th Edition, 2004.

18. Granger JP, Alexander BT, Bennett WA, Khalil RA. Pathophysiology of pregnancy-induced hypertension. Am J Hypertens. 2001;14(6 Pt 2):178S-85S.

19. Ferrazzani S. Hypertension in Pregnancy. Saudi J Kidney Dis Transpl. 1999;10:298-312.

20. Yang M, Shen W, Chen L. Pregnancy induced hypertension complicated acute disseminated intravascular coagulation: clinical analysis of 26 cases Zhonghua Fu Chan Ke Za Zhi. 1999;34(10):600-2.

21. Maslow AD, Breen TW, Sarna MC, Soni AK, Watkins J, Oriol NE. Prevalence of coagulation abnormalities associated with intrauterine fetal death. Can J Anaesth. 1996;43(12):1237-43.

22. Nolan TE, Smith RP, Devoe LD. Department of Obstetrics and Gynecology, Medical College of Georgia, Augusta 30912-3345. 1993;169(2 Pt 1):265-8.

23. Parasnis H, Raje B, Hinduja IN. Relevance of plasma fibrinogen estimation in obstetric complications. J Postgrad Med. 1992;38:183.

24. Chandran R, Adeeb NRoutine coagulation tests in cases of missed abortion. 1992;47(4):287-9. 
25. Department of haematology, university Hospital of Wales, Cardiff UK. 1990;20 suppl1:14-29.

26. Gochberg SH, Reid DE. Early Induction of Labor in Intrauterine Death J Med. 1966;275:432-4.

27. Mammen EF. Preeclampsia, delivery, and the hemostatic system. Clinical Obstetrics and gynecology. 1964;7(2):271-85.

28. Mondragon's Pregnancy information, Intra uterine fetal Death. 2010.
29. Trott EL. Hypofibrinogenaemia in obstetrics Complications, Durban, 1957.

30. Edward M. Barczak in 1955.

31. Mack HC. Plasma protein in toxemia of pregnancy, 1951

32. Mary Part Fitzgerald, MB, BCh, Claro Floro, MD, Jamie Siegel, MD, Enrique Hernandez, MD

33. Eichinger S, Sorde PM. Med student. 2004/2003.

Cite this article as: Kanchana A, Girijavani DSS.

Fibrinogen levels helps in early detection of

abnormal pregnancies. Int J Reprod Contracept

Obstet Gynecol 2017;6:232-9. 